\title{
Sex Differences in the Effect of Prenatal Testosterone Exposure on Steroid Hormone Production in Adult Rats
}

\author{
E. DOMONKOS ${ }^{1}$, V. BORBÉLYOVÁ ${ }^{1}$, L. KOLÁTOROVÁ ${ }^{2}$, T. CHLUPÁČOVÁ ${ }^{2}$, \\ D. OSTATNÍKOVÁ ${ }^{3}$, J. HODOSY ${ }^{1,3}$, L. STÁRKA ${ }^{2}$, P. CELEC ${ }^{1,4,5}$
}

${ }^{1}$ Institute of Molecular Biomedicine, Faculty of Medicine, Comenius University, Bratislava, Slovakia, ${ }^{2}$ Institute of Endocrinology, Prague, Czech Republic, ${ }^{3}$ Institute of Physiology, Faculty of Medicine, Comenius University, Bratislava, Slovakia, ${ }^{4}$ Institute of Pathophysiology, Faculty of Medicine, Comenius University, Bratislava, Slovakia, ${ }^{5}$ Department of Molecular Biology, Faculty of Natural Sciences, Comenius University, Bratislava, Slovakia

Received April 24, 2017

Accepted May 26, 2017

\section{Summary}

Maternal hyperandrogenism during pregnancy might have metabolic and endocrine consequences on the offspring as shown for the polycystic ovary syndrome. Despite numerous experiments, the impact of prenatal hyperandrogenic environment on postnatal sex steroid milieu is not yet clear. In this study, we investigated the effect of prenatal testosterone excess on postnatal concentrations of luteinizing hormone, corticosterone and steroid hormones including testosterone, pregnenolone, progesterone, estradiol and 7 $\beta$-hydroxyepiandrosterone in the offspring of both sexes. Pregnant rats were injected daily with either testosterone propionate or vehicle from gestational day 14 until parturition. The hormones were evaluated in plasma of the adult offspring. As expected, females had lower testosterone and higher pregnenolone, progesterone and estradiol in comparison to males. In addition, corticosterone was higher in females than in males, and it was further elevated by prenatal testosterone treatment. In males, prenatal testosterone exposure resulted in higher 7 $\beta$-hydroxyepiandrosterone in comparison to control group. None of the other analyzed hormones were affected by prenatal testosterone. In conclusion, our results did not show major effects on sex hormone production or luteinizing hormone release in adult rats resulting from testosterone excess during their fetal development. However, maternal hyperandrogenism seems to partially affect steroid biosynthesis in sex-specific manner.

\section{Key words}

Androgen - Estrogen - Gonadotropins • Glucocorticoid • Steroidogenesis • Prenatal androgenization

\section{Corresponding author}

P. Celec, Institute of Molecular Biomedicine, Faculty of Medicine, Comenius University, Sasinkova 4, 81108 Bratislava, Slovakia. E-mail: petercelec@gmail.com

\section{Introduction}

Exposure of female fetuses to excess testosterone during the early life may induce polycystic ovary syndrome (PCOS)-like phenotype (Stikkelbroeck et al. 2003). Although it has been suggested, that the time of androgen exposure during the prenatal life may have a significant role in future appearance of PCOS, the critical periods for the development of PCOS are unknown yet (Ramezani Tehrani et al. 2014). Animal models using rhesus monkeys (Dumesic et al. 2007), sheeps (Padmanabhan and Veiga-Lopez 2013) as well as rodents (Ramezani Tehrani et al. 2014, Roland and Moenter 2014) can mirror some of the reproductive (Rhees et al. 1997, Wolf et al. 2002, Wu et al. 2010, Yang et al. 2011, Tehrani et al. 2014, Padmanabhan et al. 2015, Veiga-Lopez et al. 2016) and metabolic (Yang et al. 2011, Sun et al. 2012, Abruzzese et al. 2016) features of PCOS observed in women. Furthermore, disturbed production of steroid hormones, including enhanced placental (Sun et al. 2012) and ovarian steroidogenesis (Wu et al. 2010, Yang et al. 2011, Amalfi et al. 2012) and, on the contrary, decreased intrafollicular steroid concentration (Veiga-Lopez et al. 2016) has been shown in prenatally androgenized (PA) female offspring. 
Moreover, androgens can organize the hypothalamicpituitary-adrenal stress response (McCormick and Mahoney 1999). Therefore it was suggested, that prenatal androgenization of female fetuses may lead to adrenal hyperandrogenism, at least to increased production of dehydroepiandrosterone (DHEA) under basal condition, and to adrenocorticotropic hormone (ACTH)-induced overproduction of DHEA, androstenedione and corticosterone (Zhou et al. 2005). At the neuroendocrine level, prenatal testosterone excess can result in disturbed regulation of secretion of the luteinizing hormone (LH) (Cardoso et al. 2016). Enhanced LH secretion may be attributed to impaired inhibitory feedback of estradiol at the hypothalamus and pituitary level (Sarma et al. 2005, Jackson et al. 2009) or to reduced peripheral sensitivity to other hormones (Cardoso et al. 2016). On the other hand, a low incidence of the preovulatory, estradiol-induced, LH surge was observed in testosterone-exposed females (Padmanabhan et al. 2015), which is probably caused by the suppressive effects of prenatal androgens on the expression of progesterone receptors in the hypothalamus (Foecking et al. 2005, Wu et al. 2010).

The pathophysiological consequences of prenatal androgen excess in males are understudied. However, some evidence shows that maternal hyperandrogenism can result in metabolic (Lazic et al. 2011) and reproductive dysfunctions also in the male offspring (Wolf et al. 2002, Ramezani Tehrani et al. 2013). The contradictory results observed in experiments focusing on the effects of prenatal androgen excess on postnatal steroidogenesis might be due to variable time, duration and dose of testosterone application (Ramezani Tehrani et al. 2013). In addition, prenatal testosterone seems to have an opposing effect on the hypothalamopituitary-gonadal axis at the pituitary and gonadal level. While the pituitary gland shows an enhanced responsiveness to the gonadoliberin accompanied by an overproduction of gonadotropins in both sexes (RojasGarcía et al. 2010), testicular Leydig cells in males have reduced sensitivity to LH (Recabarren et al. 2012, Recabarren et al. 2013).

Sex differences in the production of sex steroid hormones in the adulthood might be caused by several mechanisms (Kushnir et al. 2010). However, whether they may be affected by prenatal testosterone is yet unexplored. Therefore, in this study, we aimed to examine the effect of prenatal testosterone exposure on the production of sex hormones and their precursors, as well as on the synthesis of selected other steroids in both sexes. In addition, the plasma concentration of $\mathrm{LH}$, regulating the secretion of sex hormones production through the hypothalamo-pituitary-gonadal axis was evaluated.

\section{Material and Methods}

\section{Animals and treatment}

Lewis female and male rats were used as parental animals (10-13-week-old, Anlab, Prague, Czech Republic). Two female rats were mated with one male per cage. Detection of sperms in the vaginal smear was taken as evidence of mating considered as insemination and it served to calculate gestational days (GD). From day of insemination (GD0), dams were housed individually in polycarbonate cage $(36 \times 20 \times 19 \mathrm{~cm})$. All animals in the experiment had ad libitum access to food and water and were kept under 12:12 light-dark cycle in a controlled environment with $25 \pm 2{ }^{\circ} \mathrm{C}$ temperature and $55 \pm 10 \%$ humidity. All procedures were carried out in accordance with the Slovak legislation and were approved by the local ethical committee at the Institute of Molecular Biomedicine, Comenius University, Bratislava.

From GD14 until parturition (GD21-22) pregnant dams received daily intramuscular injection of either testosterone propionate at a dose of $2 \mathrm{mg} / \mathrm{kg}$ (Sigma-Aldrich, Munich, Germany) or vehicle (olive oil; Galvex, Banská Bystrica, Slovakia), and were allowed to deliver spontaneously (Juarez et al. 1998). Following the weaning, the offspring was caged in groups of same-sex littermates (2-4 per cage). To analyze the hormonal profile of the offspring, 7 female and 7 male rats were used from both groups - animals prenatally exposed to testosterone excess and controls.

\section{Hormonal measurements}

At the age of 12 weeks, animals were sacrificed in deep anesthesia (ketamine $100 \mathrm{mg} / \mathrm{kg}+$ xylazine $10 \mathrm{mg} / \mathrm{kg}$ ) and trunk blood was collected from the abdominal aorta. Plasma concentrations of circulating sex steroid hormones, including testosterone, estradiol, progesterone, pregnenolone and 7 $\beta$-hydroxy-epiandrosterone ( $7 \beta-\mathrm{OH}-\mathrm{EpiA})$, as well as the plasma concentration of LH and corticosterone were assessed.

Testosterone and LH concentrations were measured using commercially available ELISA kits. The analytical sensitivity of the testosterone assay was $0.083 \mathrm{ng} / \mathrm{ml}$. The inter- and intra-assay coefficients of 
variations were below $5 \%$ (DRG Diagnostic, Marburg, Germany). The sensitivity of analysis of the LH ELISA assay was $0.313 \mathrm{ng} / \mathrm{ml}$. Inter- as well as intra-assay variation of analysis were less than $5 \%$ (Shibayagi Co., Ltd, Ishihara, Shibukawa, Japan).

The concentrations of pregnenolone, progesterone, corticosterone, $7 \beta-\mathrm{OH}-\mathrm{EpiA}$ and estradiol were measured using liquid chromatography coupled with tandem mass spectrometry (LC-MS/MS) employing methods described elsewhere (Sosvorova et al. 2015, Vitku et al. 2015, Vitku et al. 2016).

\section{Statistical analysis}

To evaluate the endocrine effects of prenatal testosterone administration in the offspring, and in parallel to detect sex differences, two-way ANOVA (one factor being treatment and second being sex) with subsequent Bonferroni post hoc test was used. The F and $t$ values describe the results of the ANOVA and the subsequent pairwise comparisons, respectively. The differences between groups were considered statistically significant, if $p<0.05$. Data are presented as mean + standard deviation (SD). Statistical analyses were conducted using GraphPad Prism 6 (GraphPad Software, Inc., La Jolla, CA, USA).

\section{Results}

Plasma testosterone concentrations differed between the experimental groups (Fig. 1A, F=30.8, $p<0.001)$. Females had in comparison to males 6.5- and 7 -fold lower concentration of testosterone in plasma in the control (females: $0.29 \pm 0.12 \mathrm{ng} / \mathrm{ml}$ vs. males: $1.93 \pm 0.52 \mathrm{ng} / \mathrm{ml}, \mathrm{t}=3.04, p<0.05)$ and in the testosterone group (females: $0.43 \pm 0.35 \mathrm{ng} / \mathrm{ml}$ vs. males: $3.02 \pm$ $1.91 \mathrm{ng} / \mathrm{ml}, \mathrm{t}=4.81, \mathrm{p}<0.001)$, respectively. Prenatal testosterone treatment did not affect plasma testosterone concentrations in the adulthood $(\mathrm{F}=2.62, p=0.12)$. The interaction between sex and treatment was not significant $(\mathrm{F}=1.57, p=0.22)$. The groups did not differ in LH concentration. Neither gender $(\mathrm{F}=0.32, p=0.58)$ nor treatment $(\mathrm{F}=0.08, p=0.78)$ had a significant effect on $\mathrm{LH}$ in plasma, and no interaction between sex and treatment was found (Fig. $1 \mathrm{~B}, \mathrm{~F}=0.36, p=0.55$ ).

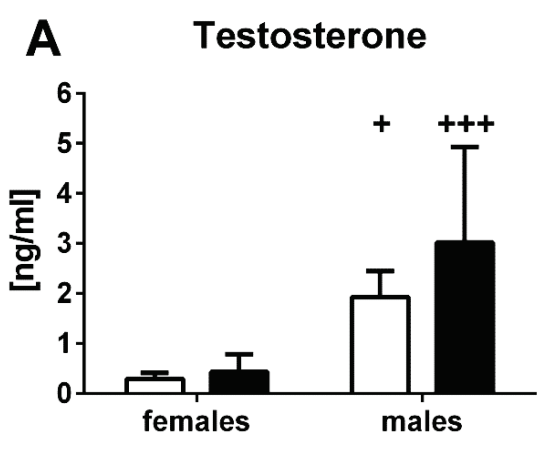

\section{B Luteinizing hormone}

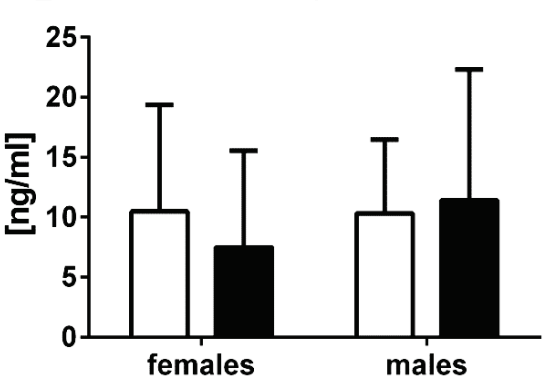

Fig. 1. Testosterone (A) and luteinizing hormone (B) concentration in rat plasma. Males have significantly higher concentration of testosterone in plasma than females in both the control $(p<0.05)$ and in testosterone exposed group $(p<0.001)$. Data are presented as mean + SD. $+p<0.05,+++p<0.001,+$ signs sex differences.

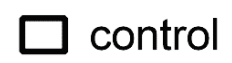

\section{testosterone}

Significant sex differences were found in pregnenolone (Fig. 2A, F=44.7, $p<0.001$ ), progesterone (Fig. 2B, $\mathrm{F}=12.8, p<0.01$ ) and estradiol concentration (Fig. 2C, $\mathrm{F}=17.5, \quad p<0.001$ ). In females, statistical analysis revealed higher progesterone (females: $2.73 \pm 2.18 \mathrm{ng} / \mathrm{ml}$ vs. males: $0.72 \pm 0.29 \mathrm{ng} / \mathrm{ml}, \mathrm{t}=2.97$, $p<0.05$ ) and estradiol (females: $0.02 \pm 0.01 \mathrm{ng} / \mathrm{ml}$ vs. males: $\quad 0.007 \pm 0.002 \mathrm{ng} / \mathrm{ml}, \quad \mathrm{t}=3.51, \quad p<0.001$ ) concentration in comparison to males only in animals that were prenatally exposed to testosterone. In the particular control groups, there was a non-significant trend to higher concentrations of these hormones in females compared to males $(p=0.09$ and $p=0.05$, respectively). Plasma pregnenolone was by $85 \%$ higher in females than in males, regardless of the treatment (in controls: females: $1.82 \pm 0.87 \mathrm{ng} / \mathrm{ml}$ vs. males: $0.26 \pm 0.12 \mathrm{ng} / \mathrm{ml}, \mathrm{t}=5.51$, $p<0.01$ and in groups prenatally treated with testosterone: females: $2.79 \pm 1.25 \mathrm{ng} / \mathrm{ml}$ vs. males: $0.32 \pm 0.17 \mathrm{ng} / \mathrm{ml}$, $\mathrm{t}=6.07, p<0.001)$. The effect of prenatal treatment on plasma concentrations of pregnenolone $(\mathrm{F}=2.85, p=0.11)$, progesterone $(\mathrm{F}=0.99, p=0.33)$ or estradiol $(\mathrm{F}=0.63$, $p=0.44$ ) in the adulthood was not significant. Similarly, no significant sex $\mathrm{x}$ treatment interaction was found (pregnenolone: $\mathrm{F}=2.27, p=0.15$; progesterone: $\mathrm{F}=0.38$, $p=0.54$; estradiol: $\mathrm{F}=0.61, p=0.45$ ).

Plasma concentration of $7 \beta-\mathrm{OH}-\mathrm{EpiA}$ was significantly affected by prenatal testosterone (Fig. 2D, $\mathrm{F}=6.64, p<0.05)$. The Bonferroni post hoc test revealed 
a significant difference with $66.7 \%$ higher concentration of $7 \beta-\mathrm{OH}-\mathrm{EpiA}$ in males prenatally exposed to testosterone excess in comparison to control males (testosterone group: $0.06 \pm 0.03 \mathrm{ng} / \mathrm{ml}$ vs. control group: $0.02 \pm 0.02 \mathrm{ng} / \mathrm{ml}, \quad \mathrm{t}=2.58, \quad p<0.05)$. Such effect of treatment was not observed in females (testosterone group: $0.06 \pm 0.03 \mathrm{ng} / \mathrm{ml}$ vs. control group: $0.04 \pm 0.02$ $\mathrm{ng} / \mathrm{ml}, \mathrm{t}=1.06, p=0.60)$. Neither the effect of $\operatorname{sex}(\mathrm{F}=1.26$, $p=0.27$ ), nor the interaction between sex and treatment ( $\mathrm{F}=1.16, p=0.29)$ were significant statistically.
A Pregnenolone
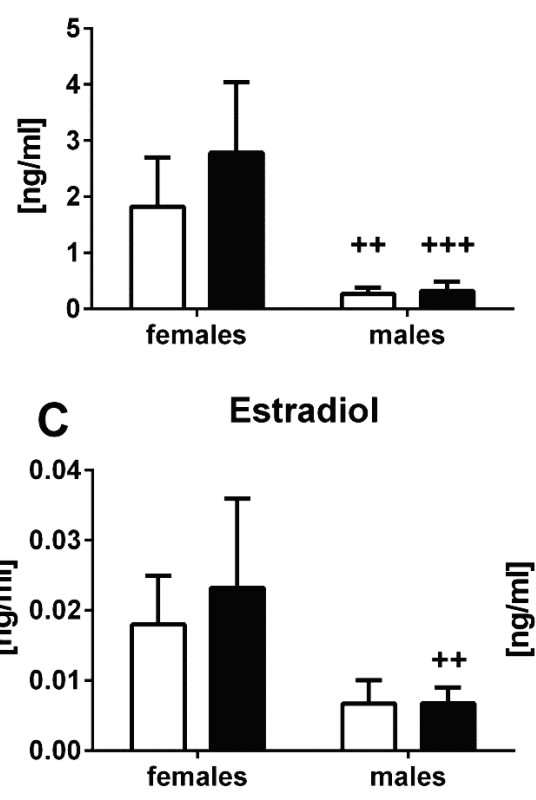

B

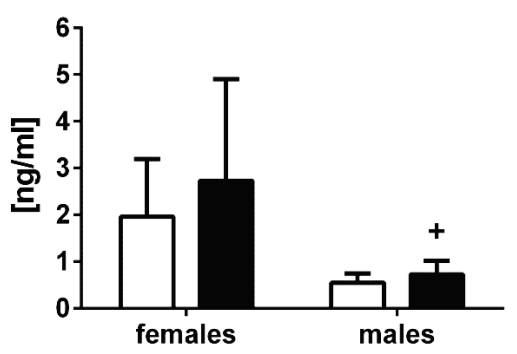

D7 $\beta$-hydroxy-epiandrosterone

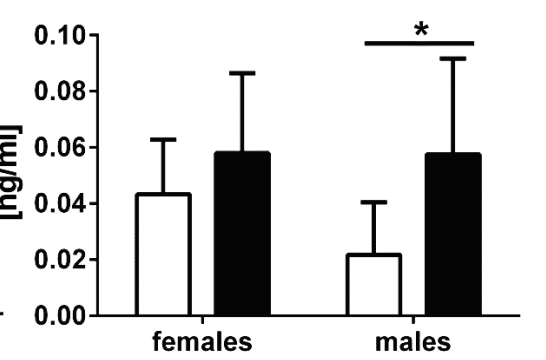

Fig. 2. Pregnenolone (A), progesterone (B), estradiol (C) and 7 $\beta$-hydroxy-epiandrosterone (D) concentration in rat plasma. Males have significantly lower concentration of pregnenolone in plasma than females in both the control $(p<0.001)$ and in testosterone exposed group $(p<0.001)$. Prenatally testosterone exposed males have lower concentration of progesterone $(p<0.05)$ and estradiol $(p<0.01)$ in comparison with prenatally testosterone exposed females. Testosterone exposed males have higher $7 \beta$-hydroxy-epiandrosterone concentration than control males. Data are presented as mean + SD. $+\mathrm{p}<0.05,++\mathrm{p}<0.01$, $+++\mathrm{p}<0.001, * \mathrm{p}<0.05, \quad+$ signs sex differences, $*$ signs the treatment effect.

\section{Corticosterone}

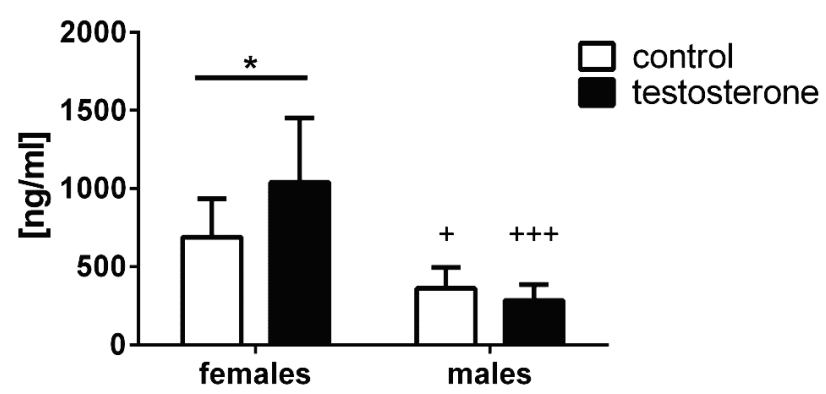

Fig. 3. Corticosterone concentration in rat plasma. Males have significantly lower concentration of corticosterone in plasma than females in both the control $(p<0.05)$ and in testosterone exposed group $(p<0.001)$. Prenatally testosterone exposed females display higher concentration of corticosterone $(p<0.05)$ than control females. Data are presented as mean + SD. $+p<0.05$, $+++p<0.001, * p<0.05,+$ signs sex differences, $*$ signs the treatment effect.

Figure 3 shows a significant sex difference in plasma corticosterone $(\mathrm{F}=31.8, p<0.001)$. Females had higher corticosterone concentration in both, the control (by $47.6 \%$, females: $689 \pm 246 \mathrm{ng} / \mathrm{ml}$ vs. males: $361 \pm 134 \mathrm{ng} / \mathrm{ml}, \mathrm{t}=2.42, p<0.05)$ and testosterone-exposed groups (by $72.7 \%$, females: $1039 \pm 412 \mathrm{ng} / \mathrm{ml}$ vs. males: $284 \pm 103 \mathrm{ng} / \mathrm{ml}, \mathrm{t}=5.56, p<0.001)$. Prenatal testosterone treatment had no effect on the concentration of corticosterone $(\mathrm{F}=2.00, p=0.17)$. However, there was a significant interaction between gender and treatment $(\mathrm{F}=4.95, p<0.05)$. While prenatal testosterone did not affect corticosterone in males $(\mathrm{t}=0.57, p>0.99)$, females prenatally treated with testosterone had 1.5-fold higher corticosterone concentration than control females $(\mathrm{t}=2.57$, $p<0.05)$.

\section{Discussion}

In the present study, sex differences in plasma steroid hormones, such as pregnenolone, progesterone, corticosterone, testosterone and estradiol were shown in adult rats regardless of the prenatal testosterone treatment. While prenatal testosterone increased the secretion of corticosterone in females and the production of $7 \beta-\mathrm{OH}-\mathrm{EpiA}$ in males, prenatal testosterone exposure affected the concentrations of other examined steroid hormones neither in females, nor in males. 
Production of pregnenolone by the conversion of cholesterol catalyzed by the cytochrome $\mathrm{P} 450$ cholesterol side-chain cleavage enzyme (P450scc) is the first committed step in the biosynthetic pathway of all steroid hormones (Hu et al. 2010). Our results indicate that prenatal testosterone does not disturb initiation of steroidogenesis, but might partially affect the metabolism of several precursors in sex-specific manner. Higher corticosterone concentrations in females treated prenatally with testosterone, in comparison to control females, suggest that in the female offspring prenatal testosterone can lead to enhanced secretion of adrenal steroids. In PA female rhesus monkeys ACTH injection induced adrenal hyperandrogenism accompanied by increased corticosterone production. However, in these animals the most of adrenocortical steroids, including glucocorticoids, were not elevated when they were evaluated under basal condition. On the other hand, dexamethasone-induced negative feedback on the ACTH secretion was not able to suppress corticosterone concentration in these PA females (Zhou et al. 2005). In accordance with that, enhanced basal ACTH secretion or higher sensitivity of the adrenal gland, mainly in zona fasciculata, to its regulators could be assumed in our paradigm of prenatal androgenization of female offspring. Furthermore, an enhanced enzymatic activity of 3 $\beta$-hydroxysteroid dehydrogenase in PA female monkeys has been suspected to increase conversion of pregnenolone to progesterone, which is a key substrate for corticosterone production, instead of the metabolism of pregnenolone towards androgens through 17a-hydroxypregnenolone (Zhou et al. 2005). This hypothetical mechanism is supported by higher progesterone observed in female rats prenatally exposed to testosterone or dihydrotestosterone on GD16-19 (Wu et al. 2010, Amalfi et al. 2012). In our study, no differences between testosterone-treated and control females were observed in plasma progesterone. On the other hand, there is evidence of reduced $3 \beta$-hydroxysteroid dehydrogenase gene expression in the granulose cells resulting in reduced progesterone production capacity in PCOS women (Doldi et al. 2000). Another published experiment in rats showed that prenatal testosterone exposure does not affect corticosterone in adult female offspring (Sun et al. 2012). Lower dose of testosterone, different vehicle and older age at corticosterone evaluation in our experiment in comparison with mentioned study could explain the contradictory results. Further studies are surely needed to investigate the mechanisms underlying the finding of higher corticosterone concentrations in females treated prenatally with testosterone.

Androgens can be synthesized from pregnenolone via two different pathways: 1) involving production of progesterone, which is converted to androstenedione via 17a-hydroxyprogesterone, 2) involving production of DHEA, which is further converted to either androstenedione or androstenediol. Besides its importance as the most abundant circulating androgen in males, testosterone is also the main precursor of estrogens in women. Testosterone is partially aromatized to estradiol also in males. Unlike most of the recent studies, in our experiment neither testosterone, nor estradiol concentration were affected by prenatal testosterone administration. However, the results of the studies examining the effect of prenatal testosterone on adult sex hormone concentrations are inconsistent. While subcutaneous injection of $3 \mathrm{mg}$ testosterone per day on GD16-19 resulted in lower testosterone concentration in adult male rats, single injection of $20 \mathrm{mg}$ testosterone on GD20 had no effect when compared to control offspring (Ramezani Tehrani et al. 2013). A dose-response study showed that although a lower dose of prenatal testosterone treatment $(0.5 \mathrm{mg}$ daily from GD14-19) is sufficient to induce a 10-fold elevation of maternal circulating testosterone and masculinization of reproductive organs of the female offspring, to markedly increase fetal testosterone concentration a higher dose (at least $1 \mathrm{mg}$ ) is needed (Wolf et al. 2002). On the contrary, increased secretion of LH-stimulated androstenedione was found in vitro in the thecal cells of follicles of PA female sheep. Interestingly, these PA females did neither exhibit increased plasma concentration of androgens, estrogens or gonadotropins (Hogg et al. 2012). On the other hand, adult male offspring of ewes exposed to testosterone propionate injections exhibited higher plasma testosterone then control males (Recabarren et al. 2013). In several published experiments on rats, PA females had higher plasma testosterone (Wu et al. 2010, Yang et al. 2011, Amalfi et al. 2012) and its precursors, 17 $\alpha$-hydroxyprogesterone and androstenedione (Yang et al. 2011), as well as higher basal estradiol concentration (Wu et al. 2010) in the adulthood. Lower estradiol was found in PA female rats in proestrus, in the stage of follicular development, that usually fails in PCOS (Amalfi et al. 2012). We were able to induce higher LH production neither in PA females, nor in males, which 
is in contrast to other studies mimicking PCOS in animal models (Sarma et al. 2005, Jackson et al. 2009, Cardoso et al. 2016) or examining the effect of prenatal testosterone in males (Recabarren et al. 2012, Recabarren et al. 2013). Discrepancies between the mentioned studies, as well as the inconsistency of our results with the previously reported findings can be caused by numerous technical reasons related to the design of the experiments, but also by the use of different strains/species of the experimental animals. In addition, the evaluation of the results should take into account the factors known to influence the endocrine milieu including age and the biological cyclicity, of several hormones, both ultradian and infradian.

To the best of our knowledge, the effect of prenatal testosterone exposure on the production of $7 \beta-O H-E p i A$, an androgenic derivate of DHEA, has been examined neither in females, nor in males, yet. Since $7 \beta-\mathrm{OH}-\mathrm{EpiA}$ has been shown to exert anti-inflammatory (Hennebert et al. 2008) and cytoprotective effects (Davidson et al. 2008, Le Mee et al. 2008), including neuroprotection in neurodegenerative disorder such as Alzheimer's disease (Dudas et al. 2004), we considered the investigation of the effects of prenatal testosterone on production of $7 \beta-\mathrm{OH}-\mathrm{EpiA}$ in the adulthood as important. The finding of higher concentration of $7 \beta-\mathrm{OH}$-EpiA in the plasma of prenatally testosterone exposed males could be of interest for further studies focusing on its potential role in the pathogenesis of both, neurodegenerative and neurodevelopmental disorders associated with prenatal hyperandrogenism, such as the autism spectrum disorder (Xu et al. 2015).

One of the major limitations of our study is that we have not analyzed the estrous cycle phase in the female offspring at sacrifice. We were not able to quantify or detect other important steroid hormones, including the main precursors of testosterone, such as DHEA, androstenedione and androstenediol, or the $5 \alpha$-reduced metabolite of testosterone and strong androgen - dihydrotestosterone. Similarly, the analysis of the expression and/or activity of the enzymes important for the metabolism of steroids, including StAR, P450scc, $3 \beta$-hydroxysteroid dehydrogenase, 17 $\alpha$-hydroxylase, $17 / 20$-lyase, aromatase and $5 \alpha$-reductase in various tissues, is missing in our study and would be valuable for the interpretation of the results.

In conclusion, our results show that prenatal testosterone exposure can partially affect the biosynthetic pathway of steroid hormones in sex-specific manner, in the absence of any changes in plasma concentration of pregnenolone, progesterone, testosterone, estradiol or LH. The mechanisms through which prenatal testosterone led to higher corticosterone in females and $7 \beta-O H-E p i A$ in males, as well as the potential causal role of these hormones in several disorders associated with prenatal androgen excess remain to be elucidated.

\section{Conflict of Interest}

There is no conflict of interest.

\section{Acknowledgement}

The study was supported by the MEYS CR (OP RDE, Excellent research - ENDO.CZ), by $\mathrm{MH} \mathrm{CZ} \mathrm{-} \mathrm{DRO}$ (Institute of Endocrinology - EÚ, 00023761), by the Slovak Research and Development Agency (APVV0753-10, APVV-0539-12) and the Comenius University (UK/308/2016).

\section{References}

ABRUZZESE GA, HEBER MF, FERREIRA SR, VELEZ LM, REYNOSO R, PIGNATARO OP, MOTTA AB: Prenatal hyperandrogenism induces alterations that affect liver lipid metabolism. J Endocrinol 230: 67-79, 2016.

AMALFI S, VELEZ LM, HEBER MF, VIGHI S, FERREIRA SR, OROZCO AV, PIGNATARO O, MOTTA AB: Prenatal hyperandrogenization induces metabolic and endocrine alterations which depend on the levels of testosterone exposure. PLoS One 7: e37658, 2012.

CARDOSO RC, BURNS A, MOELLER J, SKINNER DC, PADMANABHAN V: Developmental programming: insulin sensitizer prevents the GnRH-stimulated LH hypersecretion in a sheep model of PCOS. Endocrinology 157: 4641-4653, 2016.

DAVIDSON J, WULFERT E, ROTONDO D: 7beta-hydroxy-epiandrosterone modulation of 15-deoxy-delta12, 14-prostaglandin J2, prostaglandin D2 and prostaglandin E2 production from human mononuclear cells. J Steroid Biochem Mol Biol 112: 220-227, 2008. 
DOLDI N, GROSSI D, DESTEFANI A, GESSI A, FERRARI A: Polycystic ovary syndrome: evidence for reduced 3 beta-hydroxysteroid dehydrogenase gene expression in human luteinizing granulosa cells. Gynecol Endocrinol 14: 32-37, 2000.

DUDAS B, HANIN I, ROSE M, WÜLFERT E: Protection against inflammatory neurodegeneration and glial cell death by 7 $\beta$-hydroxy epiandrosterone, a novel neurosteroid. Neurobiol Dis 15: 262-268, 2004.

DUMESIC DA, ABBOTT DH, PADMANABHAN V: Polycystic ovary syndrome and its developmental origins. Rev Endocr Metab Disord 8: 127-141, 2007.

FOECKING EM, SZABO M, SCHWARTZ NB, LEVINE JE: Neuroendocrine consequences of prenatal androgen exposure in the female rat: absence of luteinizing hormone surges, suppression of progesterone receptor gene expression, and acceleration of the gonadotropin-releasing hormone pulse generator. Biol Reprod 72: 1475-1483, 2005.

HENNEBERT O, PELISSIER MA, LE MEE S, WÜLFERT E, MORFIN R: Anti-inflammatory effects and changes in prostaglandin patterns induced by $7 \beta$-hydroxy-epiandrosterone in rats with colitis. J Steroid Biochem Mol Biol 110: $255-262,2008$.

HOGG K, YOUNG JM, OLIVER EM, SOUZA CJ, MCNEILLY AS, DUNCAN WC: Enhanced thecal androgen production is prenatally programmed in an ovine model of polycystic ovary syndrome. Endocrinology 153: 450-461, 2012.

HU J, ZHANG Z, SHEN W-J, AZHAR S: Cellular cholesterol delivery, intracellular processing and utilization for biosynthesis of steroid hormones. Nutr Metab (Lond) 7: 47, 2010.

JACKSON LM, TIMMER KM, FOSTER DL: Organizational actions of postnatal estradiol in female sheep treated prenatally with testosterone: programming of prepubertal neuroendocrine function and the onset of puberty. Endocrinology 150: 2317-2324, 2009.

JUAREZ J, DEL RIO-PORTILLA I, CORSI-CABRERA M: Effects of prenatal testosterone on sex and age differences in behavior elicited by stimulus pups in the rat. Dev Psychobiol 32: 121-129, 1998.

KUSHNIR MM, BLAMIRES T, ROCKWOOD AL, ROBERTS WL, YUE B, ERDOGAN E, BUNKER AM, MEIKLE AW: Liquid chromatography-tandem mass spectrometry assay for androstenedione, dehydroepiandrosterone, and testosterone with pediatric and adult reference intervals. Clin Chem 56: 1138-1147, 2010.

LAZIC M, AIRD F, LEVINE EJ, DUNAIF A: Prenatal androgen treatment alters body composition and glucose homeostasis in male rats. $J$ Endocrinol 208: 293-300, 2011.

LE MEE S, HENNEBERT O, FERREC C, WULFERT E, MORFIN R: 7beta-hydroxy-epiandrosterone-mediated regulation of the prostaglandin synthesis pathway in human peripheral blood monocytes. Steroids 73 : 1148-1159, 2008.

MCCORMICK CM, MAHONEY E: Persistent effects of prenatal, neonatal, or adult treatment with flutamide on the hypothalamic-pituitary-adrenal stress response of adult male rats. Horm Behav 35: 90-101, 1999.

PADMANABHAN V, VEIGA-LOPEZ A: Sheep models of polycystic ovary syndrome phenotype. Mol Cell Endocrinol 373: 8-20, 2013.

PADMANABHAN V, VEIGA-LOPEZ A, HERKIMER C, ABI SALLOUM B, MOELLER J, BECKETT E, SREEDHARAN R: Developmental programming: prenatal and postnatal androgen antagonist and insulin sensitizer interventions prevent advancement of puberty and improve LH surge dynamics in prenatal testosterone-treated sheep. Endocrinology 156: 2678-2692, 2015.

RAMEZANI TEHRANI F, NOROOZZADEH M, ZAHEDIASL S, GHASEMI A, PIRYAEI A, AZIZI F: Prenatal testosterone exposure worsen the reproductive performance of male rat at adulthood. PLoS One 8: e71705, 2013.

RAMEZANI TEHRANI F, NOROOZZADEH M, ZAHEDIASL S, PIRYAEI A, HASHEMI S, AZIZI F: The time of prenatal androgen exposure affects development of polycystic ovary syndrome-like phenotype in adulthood in female rats. Int J Endocrinol Metab 12: e16502, 2014.

RECABARREN MP, ROJAS-GARCIA PP, EINSPANIER R, PADMANABHAN V, SIR-PETERMANN T, RECABARREN SE: Pituitary and testis responsiveness of young male sheep exposed to testosterone excess during fetal development. Reproduction 145: 567-576, 2013. 
RECABARREN SE, RECABARREN M, ROJAS-GARCIA PP, CORDERO M, REYES C, SIR-PETERMANN T: Prenatal exposure to androgen excess increases LH pulse amplitude during postnatal life in male sheep. Horm Metab Res 44: 688-693, 2012.

RHEES RW, KIRK BA, SEPHTON S, LEPHART ED: Effects of prenatal testosterone on sexual behavior, reproductive morphology and LH secretion in the female rat. Dev Neurosci 19: 430-437, 1997.

ROJAS-GARCÍA PP, RECABARREN MP, SARABIA L, SCHÖN J, GABLER C, EINSPANIER R, MALIQUEO M, SIR-PETERMANN T, REY R, RECABARREN SE: Prenatal testosterone excess alters Sertoli and germ cell number and testicular FSH receptor expression in rams. Am J Physiol Endocrinol Metab 299: E998-E1005, 2010.

ROLAND AV, MOENTER SM: Reproductive neuroendocrine dysfunction in polycystic ovary syndrome: insight from animal models. Front Neuroendocr 35: 494-511, 2014.

SARMA HN, MANIKKAM M, HERKIMER C, DELL'ORCO J, WELCH KB, FOSTER DL, PADMANABHAN V: Fetal programming: excess prenatal testosterone reduces postnatal luteinizing hormone, but not folliclestimulating hormone responsiveness, to estradiol negative feedback in the female. Endocrinology 146: 4281-4291, 2005.

SOSVOROVA L, VITKU J, CHLUPACOVA T, MOHAPL M, HAMPL R: Determination of seven selected neuro- and immunomodulatory steroids in human cerebrospinal fluid and plasma using LC-MS/MS. Steroids 98: 1-8, 2015.

STIKKELBROECK NM, HERMUS AR, BRAAT DD, OTTEN BJ: Fertility in women with congenital adrenal hyperplasia due to 21-hydroxylase deficiency. Obstet Gynecol Surv 58: 275-284, 2003.

SUN M, MALIQUEO M, BENRICK A, JOHANSSON J, SHAO R, HOU L, JANSSON T, WU X, STENERVICTORIN E: Maternal androgen excess reduces placental and fetal weights, increases placental steroidogenesis and leads to long-term health effects in their female offspring. Am J Physiol Endocrinol Metab 303: E1373-E1385, 2012.

TEHRANI FR, NOROOZZADEH M, ZAHEDIASL S, PIRYAEI A, AZIZI F: Introducing a rat model of prenatal androgen-induced polycystic ovary syndrome in adulthood. Exp Physiol 99: 792-801, 2014.

VEIGA-LOPEZ A, MOELLER J, ABBOTT DH, PADMANABHAN V: Developmental programming: rescuing disruptions in preovulatory follicle growth and steroidogenesis from prenatal testosterone disruption. J Ovarian Res 9: 39, 2016.

VITKU J, CHLUPACOVA T, SOSVOROVA L, HAMPL R, HILL M, HERACEK J, BICIKOVA M, STARKA L: Development and validation of LC-MS/MS method for quantification of bisphenol A and estrogens in human plasma and seminal fluid. Talanta 140: 62-67, 2015.

VITKU J, HERACEK J, SOSVOROVA L, HAMPL R, CHLUPACOVA T, HILL M, SOBOTKA V, BICIKOVA M, STARKA L: Associations of bisphenol A and polychlorinated biphenyls with spermatogenesis and steroidogenesis in two biological fluids from men attending an infertility clinic. Environ Int 89-90: 166-173, 2016.

WOLF CJ, HOTCHKISS A, OSTBY JS, LEBLANC GA, GRAY LEJ: Effects of prenatal testosterone propionate on the sexual development of male and female rats: a dose-response study. Toxicol Sci 65: 71-86, 2002.

WU X-Y, LI Z-L, WU C-Y, LIU Y-M, LIN H, WANG S-H, XIAO W-F: Endocrine traits of polycystic ovary syndrome in prenatally androgenized female Sprague-Dawley rats. Endocr J 57: 201-209, 2010.

XU X-J, ZHANG H-F, SHOU X-J, LI J, JING W-L, ZHOU Y, QIAN Y, HAN S-P, ZHANG R, HAN J-S: Prenatal hyperandrogenic environment induced autistic-like behavior in rat offspring. Physiol Behav 138: 13-20, 2015.

YANG X, ZHANG Y, WU X, BAE CS, HOU L, KUANG H, WANG Y, STENER-VICTORIN E: Cryptotanshinone reverses reproductive and metabolic disturbances in prenatally androgenized rats via regulation of ovarian signaling mechanisms and androgen synthesis. Am J Physiol Regul Integr Comp Physiol 300: R869-R875, 2011.

ZHOU R, BIRD IM, DUMESIC DA, ABBOTT DH: Adrenal hyperandrogenism is induced by fetal androgen excess in a rhesus monkey model of polycystic ovary syndrome. J Clin Endocrinol Metab 90: 6630-6637, 2005. 